\title{
Ståndssamhällets fall speglad i folkräkningsblanketter
}

Carl Mikael Carlsson

År I 749 genomfördes Sveriges första nationella folkräkning. Man hade visserligen räknat människor förut, men då för att kunna beskatta dem och då hade inte alla varit aktuella. Nu skulle alla räknas. Ett stort formulär massproducerades och skickades ut $\mathrm{i}$ landet. Varje stad och varje socken skulle ha var sitt exemplar. I formuläret listades en stor mängd kategorier av människor, baserade på olika kombinationer av ålder, kön, civilstatus och social tillhörighet. För varje kategori fick kyrkoherden fylla i det lokala antalet. Därefter samlades de ifyllda formulären ihop, sammanställdes i Stockholm och presenterades sedan för överheten. Insatsen upprepades regelbundet, först vart tredje och senare vart femte år, ändå till och med I 855 , varefter systemet ändrades i grunden. Formulärmakeri och sammanställning sköttes av bildade ämbetsmän, från $\mathrm{I} 756$ under namnet Kungliga Tabellkommissionen. ${ }^{\mathrm{I}}$

Kronans syfte med folkräkningen var att få ett begrepp om befolkningens storlek och fördelning. Men det fanns en bieffekt: När kommissionen skickade ut formulären rörde det sig inte bara om en förfrågan. Den spred också indirekt sin egen bild av hur människor skulle kategoriseras, en bild som prästerskapet var tvunget att anpassa sig till. ${ }^{2}$ Denna artikel bygger på tanken att den kategorisering av människor som presenteras i folkräkningsformulären medvetet eller omedvetet påverkade kyrkoherdens sätt att själv kategorisera, och att den sistnämndes roll som socknens patriark och läromästare gjorde att tankemönstret i någon mån även påverkade lokalbefolkningen. Samtidigt är det viktigt att komma ihåg att kommissionen med tiden öppnade upp för

Hur du refererar till det här kapitlet:

Carlsson, C. M. 20I6. Ståndssamhällets fall speglad i folkräkningsblanketter. I: Sandén, A. \& Elgán, E. (red.) Kunskapens tider: Historiska perspektiv på kunskapssambället. Pp. 96-I09. Stockholm: Stockholm University Press. DOI: http://dx.doi.org/IO.I6993/bai.g. License: CC-BY 4.0 
frågor och kommentarer från prästerskapet. I kommissionens arkiv finns ett digert material med de olika stiftens samlade kommentarer. En genomgång av materialet visar hur tydligt det är att olika människor hade olika definitioner på olika begrepp, och att kommissionen tog till sig prästerskapets synpunkter och förtydligade formulären. ${ }^{3}$ Påverkan var alltså dubbelsidig, och ledde till kategoriseringens förändring både på papperet och i folks medvetande. Det går alltså i mångt och mycket se ett specifikt formulär som ett tidsdokument, en kompromissbild av hur samhället just då uppfattades. ${ }^{4}$

I den här artikeln visar jag hur man med hjälp av dessa tidsdokument kan följa ståndssamhällets upplösning. Vid ordet ståndssamhället tänker nog de flesta på en svunnen riksdagsordning baserad på fyrståndsläran, där adel, präster, borgare och bönder bemannade varsin kammare. ${ }^{5}$ I den bemärkelsen upplöstes ståndssamhället i samma ögonblick som I 865 års riksdag avslutades. Men ståndssamhället kan också syfta på ordningen bakom riksdagsordningen, den kategorisering av människor som motiverade att man faktiskt hade fyra olika kamrar med just den uppdelningen. Det sociala ståndssamhället, brukar det kallas. När detta ståndssamhälle upplöstes är betydligt svårare att säga. Inte för att man inte känner till händelseförloppet, utan för att olika människor använder begreppen på olika sätt och därför pratar om olika saker. Många skulle rentav påstå att upplösningen ännu inte skett. ${ }^{6}$

På vilket sätt beskriver då folkräkningsformulären ståndssamhällets upplösning? Tabellformulärens disposition kan ses som en kompromiss kring hur man vid ett bestämt tillfälle skulle kategorisera människor, en kompromiss mellan folk och myndighet, med prästerskapet som förmedlande länk. Detta betyder att vi genom att studera hur stånden behandlas genom de olika upplagorna av formulär, kan se hur de får mindre och mindre plats, och därmed mindre och mindre betydelse. ${ }^{7}$

\section{När ståndssamhället var som starkast}

Frihetstiden förknippas ofta med fyrståndsläran, eftersom ståndsriksdagens makt blomstrade under den perioden. 
Ståndsrepresentationen har alltid haft motståndare, men så länge det sociala ståndssamhället var en naturlig del av samhället så hade det politiska systemet i någon mån existensberättigande. Att det sociala ståndssamhället faktiskt var starkt i mitten på I 700-talet speglas tydligt i den första upplagan av folkräkningsformuläret.

Formuläret utgörs till största delen av en tabell för kategorisering i just "stånd". Med det begreppet avses här inte bara fyrståndsläran, utan även den sociala finfördelningen inom och kring den. ${ }^{8}$ Alla väsentliga sociala situationer har fått en plats inom en struktur på tre nivåer. Den finaste skillnaden markeras med bokstäver och en lite grövre med nummer. Den grövsta indelningen syns bara indirekt, i hänvisningar mellan olika nummer. Kategori 23, för att ta ett tydligt exempel, är gemensam för barn och tjänstefolk till kategorierna I 5-22. Kategorierna I 5-23 har på så vis större koppling till varandra än till andra. Det är här vi ser fyrståndsläran. Kategorierna 5-I4 associeras till borgare, I 5-23 till bönder. Kategorierna 24-32 pekar ut

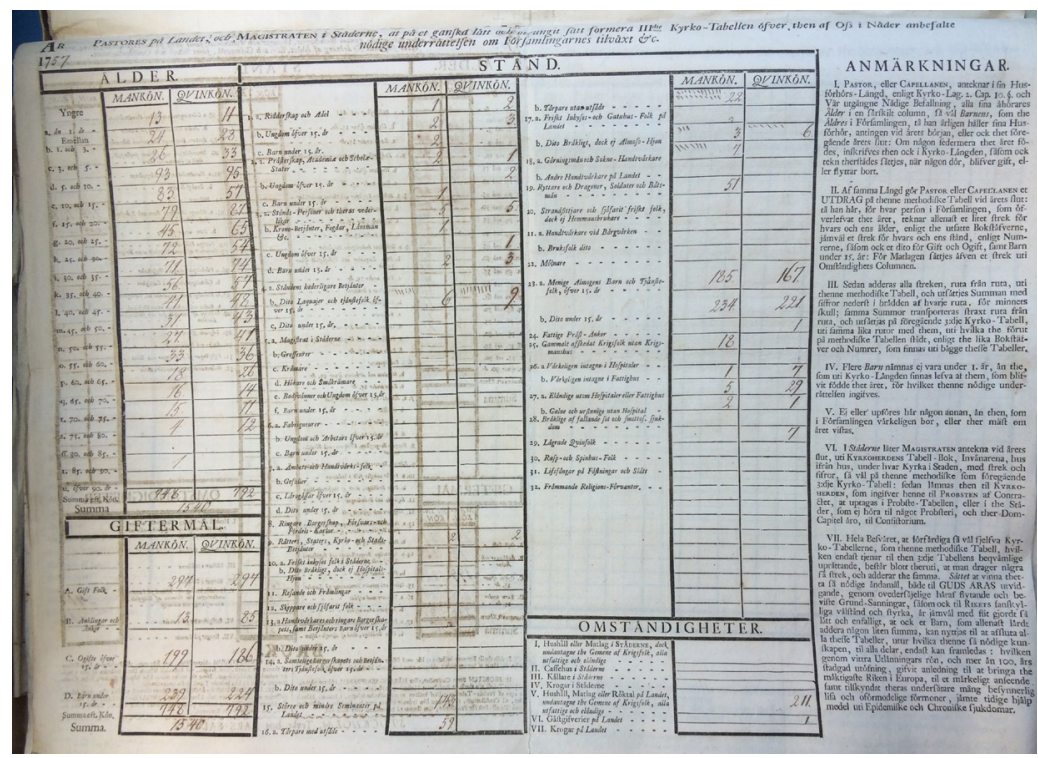

Bild 1. $I 749$ års folkräkningsformulär. Det stora antalet kategorier under rubriken "Stånd" visar att detta begrepp hade ett större omfång vid denna tid än senare. Dingtuna kyrkoarkiv (ULA), vol. G:I, Statistiska tabeller I749-I 859, Riksarkivet. Foto: Carl Mikael Carlsson. Licens CC-BY. 
samhällets utsatta eller utstötta, grupper som i en idealsituation av olika skäl inte skulle finnas. Adel och prästerskap har varsina egna numrerade kategorier.

Kategorierna 3-4 syftar på dem som från och med I 802 års formulär hänförs till som ståndspersoner, en på många sätt heterogen grupp som enkelt kunde tillskrivas en gemenskap i att den utgjordes av fint folk som inte passade in i fyrståndsläran och som därmed saknade riksdagsrepresentation. Att de ofrälse ståndspersonerna, som gruppen brukar kallas i forskarvärlden, placerades under prästerna men över borgarna är inte konstigt. Prästerna var liksom ståndspersonerna en elit, medan borgerskapet inom sitt revir, liksom bönderna inom sitt, utgjorde den stora massan.

Just det faktum att de fyra stånden inte framtäder med namn, utan genom associationer och tabellens disposition, anser jag talar för fyrståndslärans starka ställning vid denna tid. Det finns inget behov av att förklara vilket stånd som är vilket. Det är snarare en självklarhet som genomsyrar formuläret.

\section{Från stånd till yrke}

Hundra år senare, år I 855 , kom sista upplagan av folkräkningsformuläret. Mycket hade hänt sedan I749. För det första användes sedan länge olika formulär för land och stad. För det andra var strukturen mycket mer avancerad. Kategorierna var många fler, de sorterades annorlunda och olika avdelningar kunde ha olika fördelningar i axlar.

När det kommer till hur fyrståndsläran framträder i formuläret är det en väldig skillnad mellan I 749 och I 855 . Under frihetstiden hade stånden varit en naturlig kategoriseringsgrund, väl integrerad i och rentav överordnad andra sociala skiktningar. $\mathrm{Nu}$, I06 år senare, levde den kvar i fjärde artikeln som ett bihang till den huvudsakliga kategoriseringen, den "Efter Lefnadsyrken och Vilkor m. m."

Yrkeskategoriseringen hade så sent som vid folkräkningen I 850 , när I 840 års upplaga gällde, hetat "Efter Stånd och Villkor", och anknöt då alltså ännu till ståndsbegreppets äldre, vidare omfång. Följer vi kategoriseringen genom alla formulär - I749, I773, 
Formulār.

Tabell för anteckilande af Folkmängolen il. m. pá Landoloygaden.

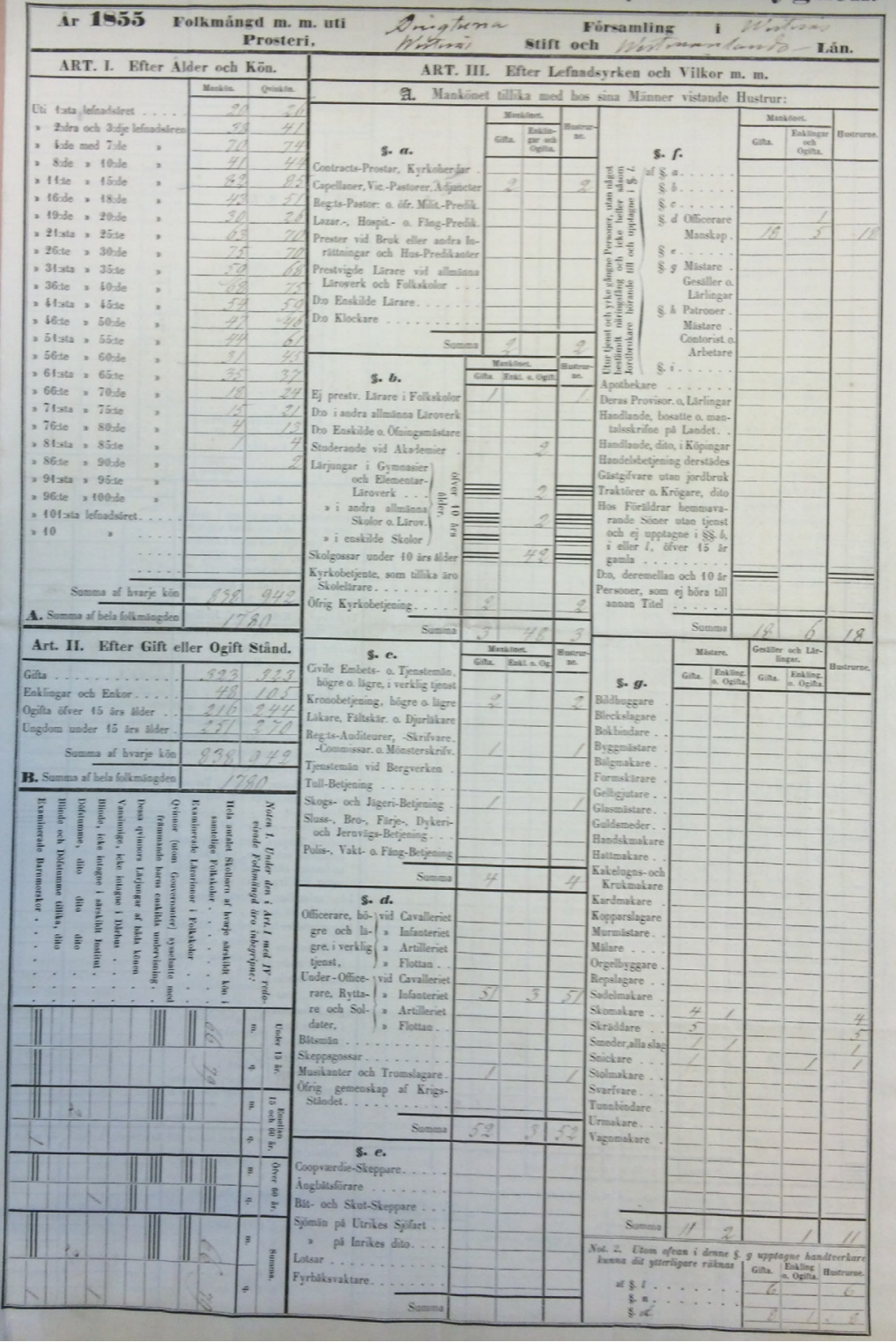

Bild 2. I 855 års folkräkningsformulär. Kategorierna är helt annorlunda sorterade än i 1749 års formulär. Notera ordet "Lefnadsyrken i rubriken! Dingtuna kyrkoarkiv (ULA), vol. G: I, Statistiska tabeller I 749-I 859 , Riksarkivet. Foto: Carl Mikael Carlsson. Licens CC-BY. 
I 802 , I 825 , I 840 , I 855 - framgår att yrke och fyrståndslära, som i I 855 års formulär alltså var noga åtskilda, hade utvecklats i olika riktningar från samma punkt: I749 var det naturligt att se verksamheten som en specialisering inom något av stånden $\mathrm{i}$ fyrståndsläran. I773 var det svårare; i den upplagan framstår de fyra ståndens överordning som påtvingad. I och med I 802 års upplaga hade kategoriseringen sprängts i två olika, så som det var ännu I 855 , det vill säga en för närings- och tjänsteförhållanden och en sammanfattande för de övergripande, politiskt relevanta ståndskategorierna. Det är lätt att såhär i efterhand se utvecklingen som ett förtydligande av äldre, dåligt strukturerade formulär, att tycka att det var klantigt av kommissionen att inte redan från början skilja mellan stånd och yrke. ${ }^{9}$ Gör man det begår man emellertid ett allvarligt misstag. I749 fanns inte den naturliga uppdelning mellan stånd och yrke som fanns I 855 . Uppdelningen är i sig någonting mer eller mindre modernt, och folkräkningens syfte är ett gott exempel på en av sannolikt många orsaker till att den blev av. Därför kunde ståndsbegreppet I749 vara så brett som det var. Syftet med folkräkningarna var till syvende och sist alltid att ge underlag för att kunna förbättra statsförvaltningen. Att det därför redan under I700-talet fanns en strävan hos tabellkommissionen att anpassa formulären för att kunna mäta ekonomiska förhållanden är inte så konstigt. Under karolinsk tid hade det inte funnits någon motsättning mellan stånd och ekonomiska förhållanden. Frälsejord och militärt befälhavande, till exempel, var adliga företeelser, skola och lärdom prästerliga. Mot slutet av I 700-talet var det inte längre så. Privilegierna var till stor del försvunna, stånd och ekonomi hade gått olika vägar. Redan I76I rapporterade tabellkommissionen följande:

Till slut uppå denna Articeln har man bordt på en gång anföra hufwud Classerna på inbyggarena i Riket [...] Närings lemmar innefatta jordbrukare, slögde ock Bergwärks arbetare [...] Tienste lemmar innebegripa Kronans Ämbetsmän ock betiänter, samt publique ock privata wärks betiänter med deras hustrur [...] Tärande lemmar, som hwarken tiäna Kronan, näringarna, eller publique ock privata wärk [...] Öfwerflödiga lemmar som lefwa af onyttiga handteringar $[\ldots]{ }^{\text {. }}{ }^{\text {o }}$ 
Här gör kommissionen en gruppindelning av befolkningen efter ekonomisk relation till stat och samhälle. Denna kategorisering är alltså, vad kommissionen anbelangar, viktigare än exempelvis ståndsindelningen. Adelsmän, till exempel, kunde tillhöra vilken som helst av dessa lemmar. Det nya tankesättet präglar redan $\mathrm{I} 773$ års formulärupplaga, samtidigt som man tydligt strävar efter att bevara de fyra ståndens överordnade ställning.

Framåt sekelskiftet I 800 visar Tabellkommissionens protokoll och korrespondens på en sådan strävan mot att kartlägga olika ekonomiska faktorer, att det inte längre kan ha varit hållbart att använda fyrståndsläran som paraplystruktur. Samtidigt var det trots allt de fyra stånden som utgjorde den gängse kategoriseringen, speglad i exempelvis politiken, så att ta bort fenomenet ur statistiken helt och hållet kom inte på fråga. I och med I 802 års formulär är det dock tydligt att kommissionen behandlar stånden sekundärt. Med andra ord: Hade ståndens självklara plats som gemene mans sociala kategoriseringsgrund inte redan börjat uppluckras, så var det bara en tidsfråga.

\section{Familjen Schenström på Bysingsberg}

I Dingtuna socken utanför Västerås ligger Bysingsbergs gård. Bysingsberg går i folkmun som herrgård, men ger ett blygsamt intryck. Den karolinska huvudbyggnaden var redan vid tillkomsten av det mindre måttet för herrgårdar, så när bygdens förmögnare bönder under tidigt I 800 -tal började tänka på sina gårdars estetik, torde Bysingsberg endast marginellt ha höjt sig över grannarna. När det kom till jordmängd, däremot, stod Bysingsberg ut. Det var under hela I80o-talet en av socknens största sammanhållna jordbruksenheter. Åren I 806-I 908 ägdes Bysingsberg av medlemmar av den regionalt prominenta släkten Schenström. Familjen Schenströms ställning ur ståndsperspektiv kan ingående följas i de ifyllda folkräknings- och andra formulär som bevarats i Dingtuna och andra socknars kyrkoarkiv och den utgör ett lysande exempel på hur formulären speglar enskilda människors ställning.

År I 806 fick Bysingsberg sin förste ofrälse ägare i brukspatronen Johan Magnus Schenström (I747-I 828), som dock aldrig 
flyttade dit. Johan Magnus var född in i ett handelshus i Västerås, engagerade sig i familjeverksamheten vid I7 års ålder, fick burskap vid 24 och blev stadens borgmästare som 29-åring. I777 lämnade han staden och övertog släktbruket i Ramnäs, där han var verksam som brukspatron i 50 år. Mot slutet av sitt liv belönades han för sin breda verksamhet med bergsråds titel och riddartecknet av Vasaorden. Bouppteckningen av år I 828 visar en säker nettoförmögenhet på närmare $\mathrm{I} 20$ ooo riksdaler, vilket är ungefär 30 gånger så mycket som vad någon av de rikaste bönderna som dog i Dingtuna på ı 820-talet lämnade efter sig. Johan Magnus var gift två gånger: först med rådmansdottern Anna Margareta Steinholz från Falun (I752-I799), därefter med häradshövdingedottern Kristina Gran från Avesta (I770-I 83 I). ${ }^{\text {I }}$

Allt detta - hem, verksamhet, ekonomi och inte minst fruarnas olika bakgrund - pekar på att Johan Magnus under sitt långa liv rörde sig från en utpräglad borgarkaraktär till en utpräglad ståndspersonskaraktär. Under sin tid i Ramnäs blev han vid varje på 1773 års formulär baserade folkräkning förd som "Bruksidkare ehvad slags Bergsbruk de drifva". ${ }^{\text {I2 }}$ Denna kategori låg utanför de fyra stånden. Hade kyrkoherden ens förknippat honom med borgerskapet hade det varit enkelt att räkna honom till borgarkategorin "Ämbetsmän och Stånds-personer, som idka Borgare-näring”, men så skedde aldrig. Detta är anmärkningsvärt, men inte konstigt, för i Ramnäsprästens ögon torde det ha varit självklart att Johan Magnus skulle räknas som bruksidkare, eftersom han idkade bruk.

I Johan Magnus bouppteckning presenteras, bland andra arvingar, åtta söner. Före namnen hedras de med titlarna "Herr Lagmannen”, "Herr Brukspatronen”, "Herr Capitainen och Riddaren”, "Herr Grosshandlaren”, “Herr”, "Herr Lieutenanten”, "Herr HofRättsnotarien” respektive "Handelsbokhållaren herr". ${ }^{\text {3 }}$ Det är tydligt att familjens karaktär av såväl borgerskap som ståndspersoner fortlevt efter Johan Magnus död. Den uppmärksamme noterar dock att femte sonen, den då 45-årige Gustav Adolf, inte ges någon annan titel än det i sammanhanget intetsägande "Herr". Orsaken är att Gustav Adolf valt en väg som var så starkt förknippad med bondeståndet att de titlar som låg nära tillhands snarare skulle sänka än framhäva hans 
ställning: jordbruket. Denna näring hade länge ansetts höra ihop med bondeståndet, men vid den här tiden hade även de högre stånden fått upp ögon för den, och de ansåg det vara skadligt att låta de obildade bönderna ensamma sköta något så viktigt. ${ }^{14}$ Utvecklingen speglas i tabellformulären: I I 802 års formulär lanserades kategorierna "Possessionater" och "Arrendatorer" som ståndspersonskomplement till "Bönder på egen jord" och "Bönder på andras jord". I dessa nya kategorier låg inte bara en förväntning på social ställning, utan också på att ståndspersonerna skulle bruka större gårdar än bönderna och snarare vara företagsledare, som brukspatronerna, än självhushållare.

Gustav Adolf Schenström (I783-I840) skrevs I797 in vid Uppsala universitet. I vilket syfte vet vi inte, men att någon med hans bakgrund bedrev högre studier var inget sällsynt. För Gustav Adolf ledde studierna emellertid ingenstans. Ingenting tyder på att han skulle ha avlagt någon högre examen. ${ }^{15}$ Han återkom så småningom till Ramnäs. Vid 23 års ålder flyttade han till Köping och tog över skötseln av gården Fantetorp. I tio års tid verkade han på Fantetorp, ogift men med hushållerska. ${ }^{16}$ Gustav Adolf mantalsskrevs, trots sin bakgrund, inte som ståndsperson. ${ }^{17}$ Fantetorp var heller ingen stor gård. Det är därför inte så konstigt att han inte räknades som arrendator i folkräkningarna I 8 IO och I8I $5 .{ }^{\text {I8 }}$ Sannolikt fördes han bland "Landtmän, som icke kunna hänföras till annan Titel". Att han skulle anses för bonde är osannolikt, inte minst med tanke på att prosten, som skötte folkräkningen, i husförhörsboken kallade Gustav Adolf "Patron". ${ }^{19}$

År I 8 I 6 gifte sig Gustav Adolf med Eva Kristina Boëthius (I792-I875) från Ludvika. De bosatte sig på Bysingsberg, som de arrenderade av Johan Magnus. Eva Kristina var dotter till en bergsman av prästsläkt och rörde sig socialt i gränslandet mellan allmoge och ståndspersoner, en gräns som just ifråga om bergsmän kunde vara väldigt flytande. ${ }^{2 \circ}$ Det är på sätt och vis samma kategoriseringssvårighet som hos den jordbrukande före detta studenten Gustav Adolf. I Dingtunas folkräkning räknades Gustav Adolf och hans hustru som arrendatorer både I 820 och I $825 .^{21}$ Sistnämnda år hade en ny formulärupplaga trätt ikraft och då specificerades arrendatorskategorin som “Arrendatorer, som ej 
tillhöra Bonde-Ståndet”. Arrendet hade blivit vanlig som legoform även hos bönder, så förtydligandet hade varit nödvändigt.

År I 827 sålde Johan Magnus Bysingsberg till Gustav Adolf. ${ }^{22}$ I folkräkningarna I 830 och I 835 räknades Gustav Adolf därför till kategorin "Possessionater utan både Caractèrer och tjenst". ${ }^{23}$ Possessionatskategorierna - det fanns även en för possessionater med karaktär men utan tjänst - kan som redan nämnts sägas ha varit den jordägande motsvarigheten till arrendatorskategorin. Possessionatsbegreppet associerades till ståndspersoner och till stor jordmängd. Det var en föregångare till godsägartiteln, men med den distans till allmogen som jordägare av större mått vid denna tid förväntades ha. Gustav Adolf var sinnebilden för den ofrälse possessionaten: en universitetsutbildad ståndspersonsson som bodde på en herrgård, men som bara levde av jorden. Han är ett tidstypiskt exempel på att det blivit socialt acceptabelt för en ståndsperson att inte bara bruka jord, utan också göra det utan att på ett eller annat sätt ha förvärvat någon titel. Detta går hand i hand med hur formulären utvecklades: I I 802 och I 825 års upplagor kategoriserades possessionater och arrendatorer i samma paragraf - paragraferna fungerade som överordnade kategorier - som avskedade ämbetsmän och andra ståndspersoner, medan bönder på såväl egen som andras jord sorterades tillsammans med resten av allmogen. I I 840 års formulärupplaga däremot, låg alla sorters jordbrukare under samma paragraf, medan avskedade ämbetsmän samsades med andra jordlösa. I och med detta led den ståndsbetingade kategoriseringen en av sina sista domänförluster mot den ekonomiska.

När I 840 års formulärupplaga togs i bruk var Gustav Adolf död. Eva Kristina räknades i folkräkningarna I 840 och I 845 till kategorin änkor "Efter Ståndspersoner, som sköta Landtbruk". ${ }^{24}$ Till folkräkningen I 850 hade dock sonen Johan Jakob Schenström (I820-I880) tagit över. Han räknades då till kategorin "Possessionater, som ej äro i verklig tjenst och icke här förut upptagne, men som äga och sköta Landtbruk". ${ }^{25}$ Johan Jakob hade tagit ännu ett steg närmare allmogen: Han saknade akademisk utbildning. I folkräkningen av år I 855 - Tabellkommissionens sista och den enda som byggde på I 855 års formulär - fanns fortfarande möjligheten att räknas som possessionat. Johan Jakob blev emellertid förd bland “Bönder på egna Hemman". ${ }^{26}$ Därmed var 
familjen Schenströms resa från borgarstånd till bondestånd fullbordad. Johan Jakob gifte sig sent - I866 - med sin hushållerska Anna Lisa Pettersson (1827-I910), själv bonddotter. ${ }^{27}$ Fyra år tidigare hade han blivit vald till nämndeman, en position som fram till I 872 enligt lag var förbehållen bönder. ${ }^{28}$

Familjen Schenströms ståndsresa var inte på något sätt en social degradering. Visst nådde Gustav Adolf aldrig sin fars ekonomiska och titelmässiga ställning, men från Gustav Adolf till Johan Jakob tycks det inte ha funnits någon materiell nedgång. ${ }^{29}$ Det som förändrades var snarare synen på vad som gav status. I formulären blev näringen och ekonomin viktigare och viktigare för den sociala ställningen, på bekostnad av de rent ståndsmässiga uttrycken. När den nya elitframhävande titeln godsägare började bli populär framåt ı 800-talets slut, användes den om såväl bönder som ståndspersoner. ${ }^{30}$ Det som var viktigt i sammanhanget var att man ägde mycket jord. Vilket stånd man tillhörde, det var oväsentligt och så småningom bortglömt.

\section{Noter}

I. För vidare läsning om Kungliga Tabellkommissionen rekommenderas: Edvard Arosenius, Bidrag till det svenska tabellverkets historia (Stockholm I928); Lennart Hennel, "Demografi som styrmedel: om det svenska Tabellverkets första tid", Arv och anor: årsbok för Riksarkivet och Landsarkiven 1996 (Stockholm I996).

2. Monika Edgren visar att den här typen av påverkan kunde vara medveten från kommissionens sida. Monika Edgren, Från rike till nation: arbetskraftspolitik, befolkningspolitik och nationell gemenskapsformering $i$ Sverige under I700-talet (Lund 200I) s. 95-96.

3. Tabellverket (f.d. Tabellkommissionen), Riksarkivet; serierna Protokoll, Koncept, Arbete med nya formulär, Berättelser till Kungl. Maj:t.

4. Jag diskuterar detta mer ingående i Carl Mikael Carlsson, Det märkvärdiga mellantinget: jordbrukares sociala status $i$ omvandling I780-I900 (Stockholm 20I6) kapitel 3.

5. Om begreppet fyrståndslära, se Kekke Stadin, Stånd och genus $i$ stormaktstidens Sverige (Lund 2004) s. 2I-22. 
6. Som exempel på studier med sinsemellan olika syn på ståndssamhället kan nämnas: Sten Carlsson, Ståndssambälle och ståndspersoner I700-I 865: studier rörande det svenska ständssambällets upplösning (Lund I949); Stadin (Lund 2004). Lars Edgren, "När skarprättaren i Malmö skulle begrava sin hustru. Ära, stånd och socialhistoriens problem", Historien, barnen och barndomarna: vad är problemet? : en vänbok till Bengt Sandin (Linköping 2009).

7. Formulären kan studeras i exempelvis: Andra befintliga längder I749-I859, Dingtuna kyrkoarkiv, Landsarkivet i Uppsala.

8. Carlsson (Stockholm 2016) s. 82.

9. Jämför Arosenius (Stockholm I928) s. 6, 4I-42, 55-56.

ıо. Tabell Commissions Berättelse om Tabell wärcket. I76I. 36§, Berättelser till Kungl. Maj:t. I76I-06-2I, Tabellverket (f.d. Tabellkommissionen), Riksarkivet.

I I. Hülphers genealogier, vol. 3, s. I 54-I55, Västerås stadsbibliotek; Leijonhufvud, Karl A. Kson, Ny svensk släktbok (Stockholm I906) s I34. Uppgifterna om förmögenhet är hämtade ur Johan Magnus Schenströms bouppteckning I828-06-I3, Bouppteckningar I 827-I829, Snevringe häradsrätts arkiv, Landsarkivet i Uppsala. Bouppteckningar I822-I893, Tuhundra häradsrätts arkiv, Landsarkivet i Uppsala.

I 2. Slutsats dragen genom jämförelse mellan Ramnäs kyrkoarkiv G: I, Statistiska tabeller I749-I859, och Ramnäs kyrkoarkiv AI:5-IO, husförhörslängder I775-I 834 .

I3. Johan Magnus Schenströms bouppteckning I828-O6-I3, Bouppteckningar I827-I829, Snevringe häradsrätts arkiv, Landsarkivet i Uppsala.

I4. Om ståndspersoners bild av bönder som varande i behov av föredöme, se Leif Runefelt, En idyll försvarad: ortsbeskrivningar, herrgårdskultur och den gamla sambällsordningen, I800-I860 (Lund 2OII) särskilt kapitel 3 .

I 5. Matrikel I76I-I833, Västmanlands-Dala nations arkiv, Uppsala universitetsbibliotek.

I6. Husförhörslängder I806-г82 I, Köpings landsförsamlings kyrkoarkiv, Landsarkivet i Uppsala. 
I7. Mantalslängder för Köpings landsförsamling I807-ı809, Kammararkivet, Riksarkivet. Vid mantalsskrivning vid den här tiden taxerades ståndspersoner annorlunda än allmogen för innehav av fönster, se Sweriges Rikes Ständers Bewillning För innewarande År I789 och the påföljande åren, til nästa Riksdag; Gjord och samtyckt wid Riksdagen I Stockholm then 28 April I789 (Stockholm I789).

I 8. Slutsats dragen genom jämförelse mellan Köpings stadsförsamlings kyrkoarkiv G:I, femårstabeller (folkräkningstabeller) mm I 749-I 830, och Köpings landsförsamlings kyrkoarkiv AI:9-Io, husförhörslängder I 806-I82I.

I9. Husförhörslängd I 8I4-I82 I, s. 242, Köpings landsförsamlings kyrkoarkiv, Landsarkivet i Uppsala .

20. Leijonhufvud, Karl A. Kson, Ny svensk släktbok, Stockholm I906, s 137. Boëthius, Bertil, Släkten Boëthius i sexton tabeller (Stockholm I962) tabellerna 3 och I3.

2I. Slutsats dragen genom jämförelse mellan Andra befintliga längder I749-I859, Dingtuna kyrkoarkiv, Landsarkivet i Uppsala, och Dingtuna kyrkoarkiv AI: I 4a-b, husförshörslängder I 8 I 5-I 824 .

22. Köpebrev anskrivet i Tuhundra häradsrätts arkiv AIIa:2, småprotokoll I 8 I 2-I 829 .

23. Slutsats dragen genom jämförelse mellan Andra befintliga längder I749-I859, Dingtuna kyrkoarkiv, Landsarkivet i Uppsala (och Dingtuna kyrkoarkiv AI: 5 a-b, husförshörslängder I 825-I 835 .

24. Slutsats dragen genom jämförelse mellan Andra befintliga längder I749-I 859, Dingtuna kyrkoarkiv, Landsarkivet i Uppsala, och Dingtuna kyrkoarkiv AI:I 6 a-b, husförshörslängder I 835-I 845 .

25. Slutsats dragen genom jämförelse mellan Andra befintliga längder I749-I859, Dingtuna kyrkoarkiv, Landsarkivet i Uppsala, och Dingtuna kyrkoarkiv AI:I7 a-b, husförshörslängder I 846-I 855 .

26. Slutsats dragen genom jämförelse mellan Andra befintliga längder I749-I859, Dingtuna kyrkoarkiv, Landsarkivet i), och Dingtuna kyrkoarkiv AI:I7 a-b, husförshörslängder I 846-I 855 .

27. Husförhörslängder I 856-ı 886, Dingtuna kyrkoarkiv, Landsarkivet i Uppsala; Anteckning om födsel I 827-05-24, Födelse- och dopbok I 824-I 87 I, Gunnilbo kyrkoarkiv, Landsarkivet i Uppsala. 
28. Sockenstämmoprotokoll I862-ı0-05, Sockenstämmans och sockennämndens protokoll och handlingar I833-1863, Dingtuna kyrkoarkiv, Landsarkivet i Uppsala; Kongl. Maj:ts Nådiga Förordning, angående ändring i wissa delar af I kap. RättegångsBalken; Gifwen Ulriksdals Slott den I9 Juli I 872 (SFS I 872 nr 55).

29. Gustav Adolf Schenströms bouppteckning I840-II-I8, Bouppteckningar I838-I854, Tuhundra häradsrätts arkiv, Landsarkivet i Uppsala; Johan Jakob Schenströms bouppteckning I880-07-I6, Bouppteckningar I87I-I886, Tuhundra häradsrätts arkiv, Landsarkivet i Uppsala.

30. Carlsson (Stockholm 20I6) s. Io7ff. 